Aletria, Belo Horizonte, v. 29, n. 4, p. 49-64, 2019

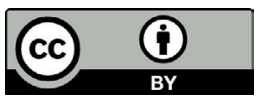

\title{
Uma alavanca em direção ao fim do mundo: H. G. Wells e sua máquina do tempo
}

\author{
A Lever Toward the End of the World: \\ H. G. Wells and His Time Machine
}

\author{
Fabio Luciano Iachtechen \\ Universidade Estadual de Ponta Grossa (UEPG), Ponta Grossa, Paraná / Brasil \\ Instituto Federal do Paraná / Paraná / Brasil \\ fabio.luciano@gmail.com
}

Resumo: A máquina do tempo, primeiro romance do escritor inglês H. G. Wells, foi, desde seu lançamento em 1895, um importante sucesso editorial, além de ter se tornado uma das mais representativas obras precursoras da moderna ficção científica. Uma de suas características essenciais é a proposta de uma viagem temporal proporcionada pela ação humana, com base no conhecimento de sua época. Ao dialogar com as premissas científicas em voga Wells criou não apenas uma máquina, mas também um conjunto de possibilidades acerca da relação humana com o tempo, concebido não mais aprioristicamente como um dado natural, mas conjecturado como um elemento possível de ser apreendido e moldado pela ação humana. Neste artigo, proponho analisar a máquina de viajar no tempo como uma criação wellsiana e discutir tanto as bases materiais e científicas que a acompanharam, bem como uma concepção históricofilosófica acerca do tempo enquanto experiência humana concreta.

Palavras-chave: H. G. Wells, A máquina do tempo; ficção científica; literatura inglesa.

Abstract: The Time Machine, the first novel by the English writer H. G. Wells, has since its launch in 1895 been an important publishing success and has become one of the precursors of the most representative works of modern science fiction. One of its essential characteristics is the proposal of a temporal journey provided by human action, based on the knowledge of its time. In dialoguing with the vogue scientific premises Wells created not only a machine, but also a set of possibilities about the human 
relationship with time, conceived no longer aprioristically as natural, but conjectured as a possible element to be grasped and shaped by human action. In this article, I propose to analyze the time-traveling machine as a Wellsian creation and discuss both material and scientific foundations that accompanied it, as well as a historical-philosophical conception of time as a concrete human experience

Keywords: H. G. Wells; The Time Machine; science fiction; English literature.

Existe apenas um tipo de história de ficção científica que eu não gosto, é a chamada viagem no tempo. Não parece lógica para mim. Por exemplo: supondo que um homem tenha rancor de seu avô, que agora está morto. Ele poderia subir em sua máquina, voltar para o ano em que seu avô era um jovem e matá-lo. Mas se fizesse isso como poderia o vingador ter nascido? Eu acho que a coisa toda é uma "mentira".

Carta de um jovem leitor de treze anos para a editoria da revista Astounding Stories, dezembro de 1931. ${ }^{1}$

A tradicional editora Zahar anunciou, em fevereiro de 2019, a publicação de uma edição de luxo, comentada, de $A$ máquina do tempo, do escritor inglês H. G. Wells, seguindo o manuscrito original de $1895 .{ }^{2}$ Ela denota um interesse perene pela obra ficcional de Wells, especialmente pelos seus romances científicos novecentistas. A esta oportuna revisita podemos acrescentar tantas outras que o número seria impossível precisar. Um dos críticos mais importantes a analisar as primeiras obras de Wells, Bernard Bergonzi, afirmou que este é um romance que, além de sua importante reputação literária, também traz consigo uma história bibliográfica rica e complexa, sem paralelos na moderna ficção inglesa. ${ }^{3}$

1 "There is only one kind of Science Fiction story that I dislike, and that is the socalled time-travelling. It doesn't seem logical to me. For example: supposing a man have a grudge against his grandfather, who is now dead. He could hop in his machine and go back to the year that his grandfather was a young man and murder him. And if he did this how could the revenger be born? I think the whole thing is the "bung". (NAHIN. Time Machines: Time Travel in Physics, Metaphysics and Science Fiction, p. 7, tradução minha)

${ }^{2}$ WELLS, H. G. A máquina do tempo: uma invenção. Tradução, apresentação e notas Adriano Scandolara. 1. ed. Rio de Janeiro: Zahar, 2019.

${ }^{3}$ BERGONZI. The Publication of The Time Machine, p. 13. 
H. G. Wells foi um contista de histórias fantásticas, de narrativas que versaram sobre sonhos humanos, sobre o tempo futuro e suas implicações sociais, além de tecnologias antevistas. Foi também precursor, ao lado do escritor francês Júlio Verne, da moderna ficção científica, embora tenha se referido por vezes aos textos desta fase inicial de sua carreira como "romances científicos". Sua imaginação foi responsável por clássicas e imperecíveis imagens simbólicas desenvolvidas pelo gênero, como a viagem temporal em A máquina do tempo (1895), a invisibilidade em $O$ homem invisivel (1896), a questão da natureza humana e seu lado bestial em A ilha do Dr. Moreau (1897), a invasão belicosa marciana em $A$ guerra dos mundos (1898) e as viagens espaciais em Os primeiros homens na Lua (1901).

Mas foi com sua máquina de viajar no tempo que Wells obteve seu primeiro sucesso editorial e de público, o que lhe permitiu, à época, deixar de lecionar como professor primário de ciências para se tornar um escritor profissional. Embora não seja a primeira narrativa com viajantes temporais, antes experenciadas em sonhos, alucinações ou hipnose, o romance é provavelmente o primeiro em que o deslocamento cronológico se dá por meio de um artefato tecnologicamente criado pelo ser humano.

De um ponto de vista simbólico, Wells criou uma máquina que se tornou ícone pop da ficção científica, reproduzida em miniaturas compartilhadas pelo universo geek e também nas versões cinematográficas que a obra recebeu, nas quais o mecanismo descrito originalmente por Wells permanece praticamente inalterado: uma espécie de gadget vitoriano que se tornou um artefato com ares steampunk. ${ }^{4}$ Com exceção das rodas, a máquina do tempo continua sendo uma espécie de automóvel, a semelhança dos primeiros veículos movidos à vapor do final do século XIX, inclusive pela presença da alavanca no lugar do volante.

Ao mesmo tempo, junto com sua criatura, a máquina do tempo, Wells criou também uma espécie de paradoxo científico: a possibilidade de uma viagem temporal, mas não espacial, a partir da ideia ainda incipiente em sua época do tempo (duração) ser possivelmente a quarta dimensão da matéria, junto à altura, comprimento e profundidade.

$\mathrm{Na}$ obra, o deslocamento para o futuro leva o viajante para uma sociedade de classes, dividida entre os Eloi, pequenas e dóceis criaturas

\footnotetext{
${ }^{4}$ É o caso da produção da MGM de 1960, dirigida por George Pal, e da versão de 2002 dirigida pelo bisneto do autor, Simon Wells.
} 
que habitam a superfície em grandes estruturas comunais, e os Morlocks, que vivem em grandes túneis subterrâneos que escondem também a maquinaria responsável pelo funcionamento daquela estrutura social. Não é intenção deste trabalho explorar esta analogia crítica à sociedade industrial inglesa, uma abordagem já oferecida por importantes estudos sobre a obra. ${ }^{5}$ A proposta aqui é analisar as características essenciais da criação de Wells, a máquina do tempo, materialização tecnológica de determinadas aspirações cientificas da época em perceber o tempo como um elemento relativo no universo natural. Esta abordagem sugere que a criação da máquina proporciona a ideia de uma viagem no tempo plausível cientificamente, e aponta para a possibilidade de uma concepção de tempo relacionada a uma determinada filosofia da história, na qual as temporalidades podem ser sobrepostas em camadas intercambiantes entre a história cronológica humana e o tempo cósmico.

\section{O tempo como duração}

A narrativa de $A$ máquina do tempo termina de uma maneira muito semelhante ao seu início, com espectadores reunidos em torno do relato das aventuras do Viajante. Este momento se assemelha a um palestrante que, depois de uma longa e concentrada exposição, aguarda a primeira questão de seu público. Não obstante, após um instante de contemplação de seus interlocutores, o Viajante se dirige ao médico e antecipa o possível raciocínio: "- Não, não posso esperar que você acredite em mim. Tome isso como uma mentira, ou uma profecia. Diga que eu sonhei isso no laboratório. Considere que eu vinha especulando sobre os destinos de nossa raça até que criei esta ficção." $\mathrm{O}$ narrador, personagem não nominado que conduz o leitor pela trama, retorna sozinho à casa do Viajante no dia posterior a esta apresentação inicial, provavelmente movido pela incredulidade, para um definitivo interrogatório.

O que presencia é uma segunda viagem, desta vez sem retorno, pois seu testemunho é dado anos depois destes episódios, tempo para

\footnotetext{
${ }^{5}$ Cf. SOUZA. O tempo e a máquina do tempo: estudos de filosofia e pós-modernidade; PHILMUS. The Logic of Prophecy in The Time Machine; HAMMOND. The Time Machine as a First Novel: Myth and Allegory in Wells's Romance.

${ }^{6}$ WELLS. A máquina do tempo, p. 112.
} 
o qual o Viajante nunca retornou, o que confirma ao narrador/leitor a veracidade de suas experiências.

Este jogo entre o verossímil e o improvável é a tônica também do início de A máquina do tempo, especialmente do primeiro capítulo dedicado à reunião inicial na casa do Viajante, na qual a ideia da viagem temporal é apresentada e debatida, ao mesmo tempo em que traz à tona algumas ideias-mestras fundamentais para esta análise.

A cena inicial, apresentada pelo narrador, desenha o confortável ambiente de uma casa ampla, na qual ocorre uma reunião de importantes personalidades locais da região de Richmond, sudeste de Londres, região de parques e espaços abertos, à margem do rio Tâmisa. Bergonzi associa este tipo de recurso literário em forma de reunião à própria cultura inglesa e sua tendência de produzir associações para diversas finalidades, tornando este elemento cultural presente na atmosfera dos gentlemen's clubs uma cena literária comum, especialmente quando os trechos subsequentes, como no caso de A máquina do tempo, apresentam uma reviravolta em relação à tranquilidade comum ao ambiente burguês vitoriano do fim do século XIX. ${ }^{7}$

Todavia, esta reunião pode ser considerada algo mais do que um simples recurso literário, pois além de figuras importantes para a comunidade local elas representam elementos simbólicos da ciência (estão presentes um médico e um psicólogo), do conhecimento e sua difusão (alguns jornalistas) e da política (o prefeito local), além de outro sujeito denominado apenas como muito jovem. Eles, de alguma maneira, formam um microcosmo social no qual a relativização do conceito de tempo conhecido até então poderia ser apresentada socialmente por seus diferentes ângulos.

A primeira questão sugerida pelo viajante é a necessidade de uma revisão dos conceitos básicos da geometria elementar ensinada nas escolas. Assim, a ideia da quarta dimensão da matéria surge como argumento fundamental que embasa a explanação, seguida da usual abordagem nominalista que caracteriza o discurso científico wellsiano.

\footnotetext{
${ }^{7}$ Bergonzi aponta ainda que $A$ máquina do tempo pertence, a partir desta estrutura inicial organizada em uma reunião, à classe das storys, à qual estão incluídos $A$ outra volta do parafuso, de Henry James, e Lord Jim, de Joseph Conrad. BERGONZI. The Early H. G. Wells: A Study of the Scientific Romances, p. 43.
} 
- Claramente, qualquer corpo real deve se estender em quatro direções: deve ter Comprimento, Largura, Espessura e Duração, - prosseguiu o Viajante do Tempo. - Mas por uma enfermidade natural da carne, a qual vou lhes explicar em um momento, tendemos a passar por cima deste fato. Há, na realidade, quatro dimensões, três das quais chamamos de planos de espaço, e uma quarta, o Tempo. Existe, no entanto, uma tendência a formar distinção irreal entre aquelas três dimensões e esta, porque nossa consciência se move intermitentemente em um único sentido, ao longo dessa última dimensão, do começo ao fim de nossas vidas. [...] É apenas outra maneira de olhar para o Tempo. Não há nenhuma diferença entre o Tempo e qualquer uma das três dimensões do Espaço, exceto a de que nossa consciência se move ao longo dela. [...] Os cientistas - prosseguiu o Viajante do Tempo, depois da pausa necessária para a assimilação do exposto - sabem muito bem que o tempo é apenas um tipo de espaço. [...] Nós estamos sempre saindo do movimento presente. Nossas existências mentais, que são imateriais e não tem dimensões, estão passando ao longo da dimensão Tempo com uma velocidade uniforme do berço ao túmulo. ${ }^{8}$

Nestes trechos pode-se perceber uma alusão à impossibilidade de se pensar o tempo - neste caso não apenas físico, mas principalmente histórico - para além de uma direção determinada, por conta de uma formação da consciência humana condicionada a este conceito de que o tempo se move em uma única direção, concepção esta que pode ser entendida como a base do pensamento histórico em fins do século XIX. $\mathrm{O}$ que observamos a seguir é a tentativa primeira em explicar o tempo como um fenômeno psicológico para, em seguida, partir para a física experimental.

A racionalidade que embasa a viagem temporal recebe especial atenção nas páginas iniciais, nas quais Wells discorre sobre o tempo como uma dimensão da consciência. O Viajante se apresenta como filósofo e oferece uma exposição sobre geometria quadridimensional, com base nos

\footnotetext{
${ }^{8}$ WELLS. A máquina do tempo, p. 12-15. A associação entre tempo e espaço como conceitos indissociáveis no universo wellsiano tem nova aparição na coletânea de contos de 1899, Tales of Space and Time.
} 
artigos do astrônomo e matemático Simon Newcomb, personagem real utilizado como recurso de verossimilhança. ${ }^{9}$ Esta primeira tentativa de explicar racionalmente a relativização das operações temporais por meio dos argumentos psicológicos, que posteriormente foram corroborados pela física experimental, pode ser entendida como representativa deste debate sobre a noção de tempo como duração.

Neste sentido, podemos tomar como exemplo a afirmação do psicólogo americano William James, em seu Principles of psychology, de 1890 , em que sugere que o que sustenta a nossa capacidade de olhar para o futuro é a ideia de duração. ${ }^{10}$ Wells certamente estava familiarizado com as ideias de James, pois além de compartilharem o mesmo editor nos Estados Unidos, Henry Holt, sua mais longeva esposa, Amy "Jane" Robbins, lhe deu uma cópia dos Principles de presente, com dedicatória de novembro de 1898, que se encontra atualmente na Wells's Collection da Universidade de Illinois Urbana-Champaign, acervo que pude consultar como pesquisador-visitante em 2013. Não é possível precisar se Wells leu o livro antes de escrever os primeiros capítulos d'A máquina do tempo,

\footnotetext{
${ }^{9}$ Refere-se ao astrônomo e matemático Simon Newcomb (1835-1909), que delineou as possibilidades de uma geometria quadridimensional como parte de uma conferência apresentada na New York Mathematical Society em dezembro de 1893. Wells provavelmente teve acesso à transcrição desta conferência publicada sob o título Modern mathematical thought na revista Nature, edição de fevereiro de 1894. A Nature é mencionada em diversos romances, como em A guerra dos mundos, especialmente nos momentos em que Wells pretende imprimir veracidade a suas informações. Seu editor na época, R. A. Gregory, foi seu amigo pessoal e colaborador da História universal, publicada em 1919.

${ }^{10}$ JAMES. The Principles of Psychology, p. 609. Outro exemplo de como a influência psicológica estava em voga no debate sobre a concepção de tempo neste período pode ser encontrada nos ensaios do filósofo francês Henri Bergson no início dos anos 1890. Particularmente, Bergson concebia o tempo como durée no seu Essai sur les donées immédiates de la conscience, de 1889. Foram notórios os debates posteriores, no início dos anos 1920, com Albert Einstein, a respeito de sua defesa do tempo como uma dimensão restrita à consciência, em um esforço de expor alguns princípios contrários à teoria da relatividade. Especificamente sobre o debate promovido na Société Française de Philosophie em seis de abril de 1922, em que Einstein acusou Bergson de literalmente não o compreender. Cf. CANALES, Jimena. "Einstein, Bergson, and the Experiment that Failed.
} 
mas alguns destes princípios podemos encontrar em outros trabalhos da fase precursora da ficção científica. ${ }^{11}$

Dando prosseguimento a suas explicações, o Viajante tenta, enfim, definir aos seus interlocutores o que é a quarta dimensão enquanto possibilidade geométrica.

Vocês sabem que numa superfície plana, que tem apenas duas dimensões, podemos representar um sólido de três dimensões; da mesma forma, eles acham que por modelos tridimensionais poderiam representar um de quatro, se conseguissem dominar a perspectiva da coisa. ${ }^{12}$

O “eles" destacado na citação é uma referência aos filósofos (como Wells os denomina), que teriam proposto a questão da geometria quadridimensional em termos conceituais. Neste trecho há menção ao mesmo professor Simon Newcomb, que hipoteticamente teria exposto o assunto à Sociedade Matemática de Nova York, exatamente um mês antes daquela reunião.

A menção às pesquisas e pensadores reais é seguida da afirmação definitiva, por parte do Viajante, de que poderia pôr em prática aquilo que até então estava sendo tratado em termos conceituais, e que tinha condições de provar suas assertivas por meio de "verificação experimental", nos seus próprios termos. As primeiras reações sobre a afirmação do Viajante em poder mover-se no tempo foram de jocosa especulação sobre a intervenção direta no passado histórico: “- Podemos aprender grego diretamente dos lábios de Homero e Platão - disse o muito jovem" ou mesmo revisitar fatos históricos, "e verificar os relatos aceitos", como, por exemplo, sobre a Batalha de Hastings. ${ }^{13}$

${ }^{11} \mathrm{O}$ mais notável exemplo de uma especulação do tempo enquanto duração é o conto The New Accelerator, de 1901, no qual um cientista concebe uma espécie de fórmula que faz com que seus sentidos, cognição e movimentos sejam mais velozes que o restante dos seres humanos. Porém, ao seu redor, o mundo continua em sua velocidade normal, quase imóvel a partir da percepção do cientista, para quem o tempo se move em um ritmo diferente.

${ }^{12}$ WELLS. A máquina do tempo, p. 13. (Grifo do autor)

${ }^{13}$ WELLS. A máquina do tempo, p. 16. Hastings foi uma batalha vencida pelos normandos em outubro de 1066, e marcou o fim da hegemonia saxônica nas ilhas bretãs. A opção de Wells em mencionar esta batalha em especificamente, dentre tantos possíveis eventos históricos a serem visitados e observados in loco, não fica clara. Hastings é 
A referida verificação experimental se configura quando o Viajante faz sua primeira demonstração, não com a máquina em si, usada em suas viagens posteriores, mas com uma pequena réplica em miniatura, descrita como um mecanismo semelhante a um relógio, com uma pequena alavanca de marfim e alguns cristais: "- Quero agora que vocês entendam claramente" diz o Viajante, "que esta alavanca, ao ser movida, faz a máquina deslizar para o futuro, e esta outra reverte o movimento", ou seja, em direção ao passado, em nenhum momento cogitado. "- Daqui a pouco vou mover a alavanca, e a máquina vai embora. Vai desaparecer, passar para o Tempo futuro, e sumir."14

Esta forma de exposição, ainda que alegórica, em que uma demonstração em escala menor é precedida pela experiência em si, é exemplar do tipo de mentalidade científica que acompanhou Wells em seus romances. Além disso, como já mencionado, a presença de uma máquina, um artefato construído tecnologicamente, ou seja, a partir do próprio conhecimento técnico transformado e materializado pela mediação da experiência, é um dado que merece atenção, pois os recursos dos deslocamentos temporais na literatura universal antes de Wells estão relacionados a elementos quiméricos e inseridos na própria mentalidade humana. Segundo Colin Manlove, antes de Wells e Verne, quando a máquina apareceu no romance vitoriano, raramente assumiu um papel central nas narrativas. Pelo contrário, em muitos casos, sua presença denuncia elementos de desumanização e depreciação social, em uma associação quase que indistinta entre ciência, tecnologia e o universo fabril. ${ }^{15}$

Como mencionado, o passado como possível experiência empírica é indiretamente descartado pelo Viajante, pois, seguindo seu entusiasmo vitoriano, interessa-lhe apenas o futuro como experiência vivida. Esta

relativamente bem documentada, especialmente se comparada às demais batalhas neste período de transição entre a baixa e alta Idade Média, não sendo, portanto, um bom exemplo de evento histórico que, ao ser contemplado diretamente por espectadores do futuro, produziria um efeito de sentido que mudaria completamente sua compreensão. Contudo, é possível supor que, sendo este evento seminal para a formação da futura nacionalidade inglesa, seja do interesse particular de Wells enquanto pesquisador da história de seu país e do próprio conceito de nação em si, do qual foi um detrator veemente.

${ }^{14}$ WELLS. A máquina do tempo, p. 19.

${ }^{15}$ MANLOVE. Wells and the Machine in Victorian Fiction. 
posição pode ser relacionada à própria física de sua época, essencialmente linear quando aborda o fenômeno temporal, e para a qual o passado é uma experiência concretizada. Ao mesmo tempo, há implícito um questionamento sobre a validade desta observação direta do passado, se ela contribuiria efetivamente para uma melhor compreensão dos fenômenos históricos ou seria apenas uma visão diferente.

O capítulo da reunião se encerra com a apresentação da máquina do tempo, em escala maior, ainda inacabada, e a promessa de uma nova demonstração, para a qual são convidados os membros da primeira reunião e alguns novos espectadores. $O$ que se segue é a cena de um jantar, no qual todos estão ao aguardo do anfitrião, que chega com as roupas rasgadas, empoeiradas e, após pedir uma pausa para se recuperar, conta a experiência de sua primeira viagem temporal, reproduzida pelo narrador anônimo.

\section{Viagem imóvel}

A experiência da viagem ao futuro transferida ao narrador não é simplesmente a descrição de um roteiro percorrido, mas um relato que procura preencher um vazio temporal com imagens que, em si, contêm muitos sentidos relacionados a diferentes ideias circulantes em sua época.

$\mathrm{Na}$ descrição do viajante, após sentar-se na máquina e empurrar para frente (em direção ao futuro) a alavanca, uma sensação desagradável lhe percorre o corpo, porém a suspeita de um engodo da consciência é desmentida pelo relógio da parede do laboratório: a impressão era de que apenas um minuto havia se passado, mas o infalível relógio apontava uma distância temporal percorrida de mais de três horas, mesmo permanecendo exatamente no mesmo lugar em seu laboratório. A surpresa inicial não the impede de ir adiante, substituindo a estranha sensação pela curiosidade do futuro enquanto experiência vivida, empurrando mais a alavanca, acelerando o avanço temporal até que a sucessão do dia e noite se transformam em uma sequência de imagens sobrepostas, quadro que pode ser associado aos cinematógrafos e sua justaposição de imagens fixas. ${ }^{16}$

\footnotetext{
${ }^{16}$ Sobre a questão do cinematógrafo, um fato digno de nota ocorreu no final de 1895 , quando Robert W. Paul, eletricista inglês, fabricante de produtos ópticos, provavelmente impressionado pela descrição das sucessões temporais em A máquina do tempo,
} 
Em determinado momento, o laboratório some, dando a entender que em um breve futuro ele já não existiria mais. No entanto, a paisagem de Richmond e do rio Tâmisa continuam familiares. $\mathrm{O}$ resultado do avanço temporal do Viajante, cada vez mais rápido em sua intensidade, é a aceleração da mudança espacial ao seu redor, o que inclui o vislumbre de uma arquitetura futurista, ainda que desfocada pela sucessão da paisagem, além da descrição da ascensão e queda de várias civilizações, uma imagem discursiva comum especialmente a historiadores vinculados a uma filosofia especulativa e fatalista da história, aos quais Wells pode ter seu pensamento associado, como Oswald Spengler e Arnold Toynbee.

O impulso final na alavanca leva o Viajante ao ano 802.701 d. C., como é possível averiguar algumas páginas adiante a partir do mostrador cronológico do painel da máquina do tempo. A data final na qual se desenrola a trama de $A$ máquina do tempo extrapola qualquer possibilidade de previsão conjectural a partir do próprio presente do Viajante, ou mesmo da nossa temporalidade atual. Mesmo assim, é uma data que, apesar do número misterioso, merece algumas considerações, pois nela podem ser encontrados alguns significados históricos para além da simples evasão cronológica.

Creio ser possível afirmar que a familiaridade de Wells com a arqueologia e a antropologia biológica de sua época possa, em alguma medida, ter influenciado na formação de sua visão de uma viagem temporal em larga escala. Como estudante de ciências em South Kensington, pertenceu às primeiras gerações de jovens a terem contato efetivo com emergentes teorias sobre a formação da Terra e do Universo,

procurou Wells para lhe propor sociedade em um invento que estava por concluir: o teatrograph, uma espécie de transmissor sequencial de imagens semelhante ao que na mesma época estavam desenvolvendo os irmãos Lumière e ao kinetoscópio de Thomas Edison. Paul propôs sociedade a Wells para produzirem filmes, a começar por uma versão cinematográfica de $A$ máquina do tempo, em que os espectadores, sentados em uma plataforma oscilante, sujeita a vento e ruídos, seriam transportados por imagens animadas de diferentes épocas do passado, presente e futuro. Wells recusou a proposta, apesar de ter confessado ser promissora e financeiramente interessante, mas que, segundo ele mesmo, seria devastadora para suas pretensões intelectuais. A resposta de Wells a Robert Paul pode ser encontrada no apêndice do estudo de Leon Stover, "Robert W. Paul on The time machine and the history movies" em STOVER. The Time Machine, an Invention: A Critical Text of the 1895 London First Edition, p. 244-245. 
sobre a origem da vida e a era dos dinossauros. Estes novos campos de conhecimento, imensos e promissores, são lembrados no epílogo de $A$ máquina do tempo quando o narrador, conjecturando sobre os possíveis destinos do viajante, imagina viagens para os períodos Paleolítico, Jurássico e Triássico.

Desta forma, diante da ampliação significativa da escala temporal possível de ser apreendida pela ciência de sua época, a humanidade emerge tardiamente na cadeia evolutiva, ainda que, ao mesmo tempo, nossa espécie possa ser considerada bastante antiga, e isso cada vez mais se confirma pelos exames laboratoriais e pela ciência antropométrica. Por exemplo, na História universal de 1919, Wells aponta o surgimento do pithecanthropus erectus (ou homem de Java) há cerca de 800.000 mil anos atrás, uma afirmação embasada nos estudos paleontológicos mais importantes de sua época. Cerca de duas décadas depois, com o advento dos exames mais apurados de radiocarbono, essa datação foi confirmada como superior aos 1,8 milhões de anos.

Neste sentido, é possível conjecturar que Wells especulava a respeito de escalas temporais maiores porque as possibilidades de mudanças significativas na estrutura social humana não poderiam ser objeto de sua análise, pelo menos dentro do modelo historiográfico estabelecido, no qual apenas uma ínfima parte da aventura humana poderia ser registrada por meio do que se considerava "documento" ou "fonte histórica". Semelhante argumento podemos encontrar no estudo proposto por Patrick Parrinder, para quem Wells estava determinado, ao propor tal escala temporal, a demonstrar os resultados danosos de um processo evolutivo estritamente natural, sem a intervenção humana em sua condução e impossível de ser apreendido racionalmente pela sua extrapolação temporal. Para Parrinder,

A evolução por seleção natural - o modelo estritamente darwinista ao qual Wells e Huxley aderiram - não poderia ter provocado mudanças significativas dentro da espécie humana na da história registrada, de modo que tais mudanças devem ser culturais, não naturais em sua origem. Wells estava determinado a mostrar os resultados da evolução natural hipotética, não de processos artificiais ou eugênicos em A máquina do tempo. A viagem do Viajante por boa parte de um milhão de anos reflete tanto 
a provável idade da espécie humana, na compreensão dos contemporâneos de Wells, quanto o tempo mínimo necessário para que a seleção natural produza novos seres degenerados descendentes da humanidade atual. ${ }^{17}$

O horizonte temporal de Wells foi também influenciado pela física de sua época, especialmente a que abordava a idade do universo e o futuro do sistema solar. Ao fim do livro, por exemplo, ao escapar dos perigos que o ano 802.701 oferecia ao viajante, ele adianta sua alavanca para frente, para cerca de 29 milhões de anos, uma provável alusão à idade dos seres vivos mais próximos de nós, após os dinossauros há cerca 65 milhões de anos. Ao menos, argumento semelhante sobre este fenômeno é apresentado nos primeiros capítulos da História universal dedicados ao desenvolvimento dos seres vivos entre o paleolítico e o neolítico. A visão descrita é de um grande sol, vermelho e intenso, que toma conta da paisagem, uma praia desolada, deserta e sem vida. Ao passo em que em termos biológicos a narrativa aponta para a plasticidade da vida, temos também uma breve, porém importante lembrança de um universo em mutação, cuja energia pode ser entendida como limitada.

Em sua imóvel trajetória, o Viajante observa diversos sinais das mudanças civilizacionais, bem como de diferentes fenômenos naturais: "[...] vi grande e esplêndida arquitetura se erguer ao meu redor, mais sólida que a de qualquer prédio de nosso tempo, e no entanto, como parecia, construída de lampejos e névoas". ${ }^{18}$ Na prática, não teriam sido necessários oitocentos mil anos para que estas mudanças ocorressem. Nosso conhecimento histórico sugere, para usar o mesmo número alegórico, que oitocentos anos seriam suficientes entre o apogeu e o fim de

17 "Evolution by natural selection - the strictly Darwinian model to which Wells and Huxley adhered - could not have brought about significant changes within the human species within recorded history, so that any such changes must be cultural, no natural in origin. Wells, was determined to show the results of hypothetical natural evolution, not of artificial or eugenics processes in The Time Machine. The traveller's voyage through the best part of a million years thus reflects both the probable age of the human species, in the understanding of Wells's contemporaries, and the minimum time needed for natural selection to produce new degenerate beings descended from present-day humanity." PARRINDER. Possibilities of Space and Time, p. 39.

${ }^{18}$ WELLS. A máquina do tempo, p. 34. 
uma civilização. ${ }^{19}$ Mesmo levando em conta a questão material, como, por exemplo, a mais durável das arquiteturas, oito mil anos seria um tempo mais do que suficiente, em hipótese, para se observar tal fenômeno, pelo menos esta é a idade das primeiras urbes humanas assim compreendidas.

Desta forma, é possível sugerir, a partir da própria suposição de como Wells chegou a esta aparentemente aleatória datação, que ela representa não apenas uma escala temporal cósmica que engloba o futuro, mas duas, o que inclui também uma escala temporal histórica medida pelo surgimento e queda de diferentes civilizações, ambas sobrepostas e intercambiantes.

Patrick Parrinder sugere, de maneira bastante plausível, que a descrição da reunião do capítulo inicial de $A$ máquina do tempo tenha sido ambientada no início do século XX, apesar de Wells não apresentar objetivamente nenhuma data. Em outros romances científicos do período, como em A guerra dos mundos ou Os primeiros homens na Lua, existe a contextualização "início do século XX”, sem maior precisão. Wells usou também este contexto-base em "Chronic argonauts", conto de 1888 e prelúdio de $A$ máquina do tempo.

Se tomarmos como base (e ponto de partida da viagem) o ano de $1901,{ }^{20}$ o universo descrito em A máquina do tempo foi exatamente imaginado como sendo 800.800 (oitocentos mil e oitocentos) anos em direção ao futuro, ao qual acrescendo os 1901 anteriores, chegamos aos 802.701 propostos por Wells. ${ }^{21}$ Temos assim representados alegoricamente os oitocentos anos de uma possível escala histórica e os oitocentos mil anos da escala cósmica bioevolutiva.

É possível identificar outros signos que fundamentam estas ideias de que o tempo tratado no romance é uma representação de estratos temporais sobrepostos. O historiador norte americano Carl Becker, por exemplo, em resenha sobre a História universal, lembra que Wells, em seus capítulos introdutórios, apresenta uma datação sugerida na época

\footnotetext{
${ }^{19}$ Neste sentido, podemos lembrar apenas como exemplo, a proposta de Oswald Spengler a respeito do caráter orgânico das civilizações. Para ele a média de vida cronológica de uma civilização não ultrapassaria os 1.000 anos, como no caso da europeia ou fáustica, como a denominara, que já se encontrava no início dos anos 1920 emanando os últimos suspiros iniciados ainda na Idade Média. Ver SPENGLER. A decadência do Ocidente. ${ }^{20}$ Este ano foi também o da publicação de Antecipations, obra em que Wells propôs uma abordagem mais direta e sociológica do futuro, principalmente o século XX.

${ }^{21}$ PARRINDER. Possibilities of Space and Time, p. 42.
} 
para a idade da Terra, provavelmente uma novidade impactante ao leitor comum. "O que impressionará particularmente o leitor, e sem dúvida é o que se pretendia, é que foi um tempo incrivelmente longo na formação, 80 ou 800 milhões de anos, mais ou menos, de acordo com as melhores suposições." E no trecho seguinte, recorda que Wells apresenta, na tábua cronológica presente ao fim da História universal, cerca de 800 mil anos como o provável início da presença humana em nosso planeta. ${ }^{22}$

As diversas ideias encontradas nos primeiros capítulos de $A$ máquina do tempo, de alguma maneira, convergem para a forma como Wells concebe o conceito de tempo, natural e historicamente, e de como este conceito está relacionado com outras ideias semelhantes em sua época. Para Wells, a partir deste momento, o futuro da humanidade se tornou um objeto de conhecimento tão maleável e sujeito à análise e interpretação quanto o presente ou o passado.

\section{Referências}

BECKER, Carl. Mr. Wells and the New History. The American Historical Review, Oxford, v. 26, n. 4, p. 641 - 656, July, 1921. DOI: https://doi. org/10.2307/1836730.

BERGONZI, Bernard. The Early H. G. Wells: A Study of the Scientific Romances. Manchester: Manchester University Press, 1961. DOI: https:// doi.org/10.3138/9781442656864.

BERGONZI, Bernard. The Publication of The Time Machine, 1894 -1895. Review of the English Studies, Oxford, v. 11, n. 41, p. 42-51, 11960. DOI: https://doi.org/10.1093/res/XI.41.42.

CANALES, Jimena. Einstein, Bergson, and the Experiment that Failed: Intellectual Cooperation at the League of Nations. Modern Language Notes, Cambridge, v. 120, n. 5, p. 1168-1191, Dec. 2005. DOI: https:// doi.org/10.1353/mln.2006.0005.

22 "What will strike the reader particularly, and doubtless was intended to, is that it was an incredibly long time in the making - 80 or 800 million years, more or less, according to the best guesses." BECKER. "Mr. Wells and the New History", p. 645. 
HAMMOND, John. The Time Machine as a First Novel: Myth and Allegory in Wells's Romance. In: PARRINDER, Patrick. H. G. Wells Perennial Time Machine. Selected Essays from the Centenary Conference "Time Machine: Past, Present and Future". London: Imperial College, 1995. p. 3-11.

JAMES, William. The Principles of Psychology. New York: Henry Holt, 1910. v. 1.

MANLOVE, Colin. Charles Kingsley, H. G. Wells and the Machine in Victorian Fiction. Nineteenth-Century Literature, Oakland, CA, v. 48, n. 2, p. 212-239, Sept.1993. DOI: https://doi.org/10.2307/2933891.

NAHIN, Paul J. Time Machines: Time Travel in Physics, Metaphysics and Science Fiction. New York: Springer-Verlag, 1999.

PARRINDER, Patrick. Possibilities of Space and Time. In:

Shadows of the Future: H. G. Wells, Science Fiction and Prophecy. New York: Syracuse University Press, 1995, p. 30-48.

PHILMUS, Robert; HUGUES, John. H. G. Wells: Early Writings in Science and Science Fiction. Berkeley: University of California Press, 1975.

SOUZA, Ricardo Timm de. O tempo e a máquina do tempo: estudos de filosofia e pós-modernidade. Porto Alegra: EDIPUCRS, 1998.

SPENGLER, Oswald. A decadência do ocidente: esboços por uma morfologia da história universal. Rio de Janeiro: Jorge Zahar, 1964.

STOVER, Leon. The Time Machine, An Invention: A Critical Text of the 1895 London First Edition. London: McFarland, 1983. 